\title{
JOAQUIM GUERRA E O DEBATE ÀS MARGENS DA TRADUÇÃO DE CONFÚCIO: MARCAS DO DISCURSO POLÊMICO
}

\author{
Chen Tsung Jye' \\ Antonio José Bezerra de Menezes Jr
}

Resumo: O presente trabalho tem por objetivo identificar as marcas do discurso polêmico encontradas nas Notas Críticas da tradução dos clássicos chineses feitas pelo jesuíta português Joaquim Guerra (1908-1993). No quadro teórico, na linha de Bakhtin e Ducrot, verifica-se como o dialógico e o polifônico concorrem para o discurso polêmico. $\mathrm{Na}$ análise do corpus, verificam-se duas estratégias discursivas baseadas no grau ou intensidade da argumentação e no ethos do enunciador-polemista, aqui designadas refutações brandas e refutações enérgicas. Nas considerações finais, procura-se identificar as vozes e motivações presentes no debate sobre a tradução dos textos confucianos.

Palavras-chave: análise do discurso, formação discursiva, polêmica, confucionismo.

AвSTRACT: This paper aims at identifying marks of the controversial speech found in Critical Notes from the translation of Chinese classics made by the Portuguese Jesuit Joaquin Guerra (1908-1993). In the theoretical framework, in line with Bakhtin and Ducrot, it can be noticed how the dialogic and polyphonic contribute to the controversial speech. When analyzing the corpus, there are two discursive strategies based on the degree or intensity of the arguments and on the ethos of the announcer-polemicist, here designated mild refutations and energetic refutations. At the final considerations, we seek to identify the voices and motivations involved in the debate about the translation of the Confucian texts. KEYWORDs: discourse analysys, discursive formations, polemics, confucianism.

I Professor Livre-Docente da Área de Língua e Literatura Chinesa do Departamento de Letras Orientais/FFLCH/USP.

2 Professor Assistente da Área de Língua e Literatura Chinesa do Departamento de Letras Orientais/FFLCH/USP. 
"Destruirei a sabedoria dos sábios
c confundirei a inteligência dos inteligentes."

\section{Introdução}

A tradução dos Clássicos Chineses para as línguas ocidentais sempre constituiu uma tarefa das mais difíceis. Muitas traduções parciais surgiram desde o século XVI, mas apenas dois autores enfrentaram a tarefa de realizar a tradução completa do cânon confuciano, a saber: o pastor protestante de origem escocesa James Legge (1815-1897) e o padre jesuíta de origem portuguesa Joaquim Angélico de Jesus Guerra (1908-1993).

A tradução de Legge, The Chinese Classics, publicada em sete volumes pela Universidade de Oxford, tornou-se a principal referência das traduções feitas em língua inglesa. Quase um século depois, entre os anos 1972 e 1987, o missionário Guerra, vivendo em Macau, irá refazer o mesmo percurso, mas adotando uma perspectiva diferente. Enquanto o trabalho de Legge seguia o modelo da escola neoconfuciana, em particular a interpretação de Zhu Xi (1130-1200), Guerra irá retomar a perspectiva dos missionários jesuítas na China nos séculos XVI-XVII, que procuraram recuperar o confucionismo original.

Nas "Notas Críticas" que acompanham seu trabalho, Guerra irá não apenas dialogar, mas travar um intenso debate com Legge e demais tradutores e intérpretes que se apoiaram no The Chinese Classics. Neste artigo procuramos examinar algumas marcas do discurso polêmico presentes nas refutações feitas por Guerra no espaço das suas "Notas Críticas", as quais ele principia dizendo:

James Legge, na sua obra monumental de tradução dos Clássicos Chineses, começou pelos diálogos, ou Confucian Analects, como ele lhes chama. Por sinal, nas Notas à sua edição, insere muitas indicações miúdas, para ir assim iniciando o seu leitor e aprendiz a sinólogo.

Não há dúvida que o seu consciencioso trabalho ajuda consideravelmente os novos tradutores, que the estamos gratos por isso. Mas é natural que, de vez em quando discordemos e lhe critiquemos a sua versão. É assim que se adianta no conhecimento dos textos, para honra dos seus autores e no interesse de todos. (GUERRA, 1984, p. 101) 


\section{Dialogismo e Polifonia no Discurso Polêmico}

Ao tratar do conceito dialógico da linguagem, desenvolvido por Bakhtin em Marxismo e filosofia da linguagem, Brait sintetiza as duas dimensões que esse conceito comporta:

Por um lado, o dialogismo diz respeito ao permanente diálogo, nem sempre simétrico e harmonioso, existente entre os diferentes discursos que configuram uma comunidade, uma cultura, uma sociedade. É nesse sentido que podemos interpretar o dialogismo como o elemento que instaura a constitutiva natureza interdiscursiva da linguagem.

Por um outro lado, o dialogismo diz respeito às relações que se estabelecem entre o eu e o outro nos processos discursivos instaurados historicamente pelos sujeitos, que, por sua vez, instauram-se e são instaurados por esses discursos. E aí, dialógico e dialético aproximam-se, ainda que não possam ser confundidos, uma vez que Bakhtin vai falar do eu que se realiza no nós, insistindo não na síntese, mas no caráter polifônico dessa relação exibida pela linguagem. (BRAIT, 1997, p. 98)

Fiorin também destaca que, embora o diálogo seja usualmente entendido como busca do entendimento, o dialógico traz consigo tanto o consenso quanto o dissenso:

O vocábulo "diálogo" significa, entre outras coisas, "solução de conflitos", "entendimento", "promoção de consenso", "busca de acordo", o que poderia levar a pensar que Bakhtin é o filósofo da grande conciliação entre os homens. Não é nada disso. As relações dialógicas tanto podem ser contratuais ou polêmicas, de divergência ou de convergência, de aceitação ou de recusa, de acordo ou de desacordo, de entendimento ou de desinteligência, de avença ou de desavença, de conciliação ou de luta, de concerto ou de desconcerto. (FIORIN, 2006, p. 24)

Segundo Maingueneau, citado por Helena Brandão, "todo discurso é constitutivamente polêmico dado o caráter heterogêneo da discursividade que faz pressupor sempre um 'avesso' sob o 'direito', o 'outro' sob o ‘um'” (BRANDÃO, 1994, p. 129). 
Ao examinar a relação interlocutiva na polêmica, Helena Brandão destaca que o discurso do oponente é apenas assumido para em seguida ser desvalorizado e a polêmica converte-se num jogo espetacularizado no qual se oferece ao outro justamente aquilo que o outro mais recusa. E conclui:

A polêmica se caracteriza, portanto, pelo contra-discurso cujos enunciados constituem formulações ao contrário. É um discurso que nega tendo como suporte o discurso negado. Sua natureza polêmica se manifesta na superfície linguística através de marcas enunciativas específicas, características dos procedimentos da refutação, da invectiva, da agressão ou da ironia. (BRANDÃO, 1994, p. 131)

Nesse sentido, o interdiscursivo que introduz e faz da alteridade o seu alvo acaba produzindo o caráter polifônico do discurso polêmico, como observa Koch:

Em se tratando de polifonia, basta que a alteridade seja encenada, isto é, incorporam-se ao texto vozes de enunciadores reais ou virtuais, que representam perspectivas, pontos de vista diversos, ou põem em jogo "topoi" diferentes, com os quais o locutor se identifica ou não. $(\mathrm{KOCH}, 2003$, p. 73)

\section{Análise do Corpus}

A tradução completa dos Clássicos Chineses para o português, levada a cabo por Joaquim Guerra ao longo de quase duas décadas de trabalho, é uma obra imensa. Compreende um total de dez volumes, com mais quinhentas páginas cada um. Trata-se de uma publicação bilíngue, trazendo juntamente com o texto original em chinês antigo a pronúncia dos caracteres chineses segundo um sistema denominado "Leitura Alfabética" (criado pelo próprio tradutor) e, ao final de cada capítulo traduzido, um conjunto de "Notas Críticas" nas quais Joaquim Guerra evoca e refuta as soluções divergentes dadas por outros tradutores, em especial a tradução feita por James Legge na coleção The Chinese Classics. É no espaço erudito e explicativo das Notas Críticas que vamos encontrar as marcas do discurso polêmico. 
Vamos delimitar e restringir o nosso corpus às Notas Críticas referentes aos cinco primeiros capítulos dos Diálogos de Confúcio (Lun Yu 論語), obra máxima da escola confuciana, que integra o volume intitulado Quadrivolume de Confúcio (GUERRA, 1984). Operando por amostragem, destacaremos apenas alguns elementos que caracterizam os procedimentos retóricos e argumentativos com os quais Joaquim Guerra questiona e mesmo afronta outros tradutores.

Considerando que a negação do discurso do outro é um dos fundamentos do discurso polêmico, vamos encontrar nas Notas Críticas dois tipos básicos de refutação: um mais brando e cordial, e outro mais enérgico e quase destemperado. Em ambos também aparece com frequência a ironia como recurso adicional para desvalorizar o discurso do outro.

\subsection{Refutações Brandas}

Neste primeiro grupo, utilizam-se os operadores mas e embora como recursos da contrajunção, assim definida por Koch:

Contrajunção - consiste na introdução da perspectiva de um outro enunciador (E1), genérico ou representante de um grupo ou de um "topos" (cf. Ducrot, 1987), ao qual se opõe o segundo enunciador, com o qual o locutor se identifica $(\mathrm{E} 2=\mathrm{L})$. Tem-se aqui, segundo Ducrot, o mecanismo da concessão: acolhe-se no próprio discurso o ponto de vista do Outro (E1), dá-se-lhe uma certa legitimidade, admitindo-o como argumento possível para determinada conclusão, para depois apresentar, como argumento decisivo, a perspectiva contrária. É este o caso de todos os enunciados introduzidos por conectores de tipo adversativo e concessivo. (KOCH, 2003, p. 70-71)

Em geral, aqui são apontados erros de caráter exegético, nos quais a interpretação equivocada do significado ou do uso sintático dos caracteres chineses resulta numa tradução incorreta ou incompleta. São pequenas censuras feitas em tom professoral.

Vejamos alguns exemplos: 
a) Mestre James Legge traduziu assim a primeira frase: (...) Mas os caracteres e a estrutura da frase dizem mais alguma coisa. [p. 101]

b) Legge traduziu: "I daily examine myself on three points". À letra o texto diz: Examino-me cada dia 3 vezes (saem). Mas eu cuido que este "saem" se deve entender, como tantas vezes, no sentido de repetidas vezes. [pp. 105 e 107]

c) Observa Legge que Tjur-Xe [Zhu Xi] entendia a palavra [pahym] no sentido de "widely". Mas não está certo. [p. 109]

d) Arthur Waley diz que a passagem não se encontra em nenhum dos livros (documentos) genuínos (...). Mas eu pergunto a Waley: Viu alguém esses documentos antigos, para saber que houve imitação? [p. 141]

e) Diz Waley: (...) Creio que lhe salva o sentido; mas está arrevezado. Em todo o caso o texto chinês nem está arrevezado, nem diz isso. [p. 147]

f) Diz Mestre Legge: (...) O texto não diz isso, mas sim: Se não for por meios honestos, não se podem procurar (Tjhux). [p. 185]

g) Diz também Mestre Legge que ele, por si traduzia: (...) mas que nenhum escritor chinês lhe aprovou tal versão. Coragem, Mestre Legge! O amor da verdade acima de tudo: da verdade, dos textos e dos seus autores. Senão, o melhor era não pôr as mãos ao trabalho. [p. 191]

h) Tjur-Xe, diz o mesmo Legge, tomou "Dsaoj.5hc" (o do texto) por "Dsao.50f", que significa Talhar fatos, resolver. Mas isso são as liberdades que ele toma com os textos. Não se pode fazer. [p. 213]

\subsection{Refutações Enérgicas}

Neste segundo grupo, recorre-se a exclamação e expressões interjetivas para produzir uma argumentação categórica e impactante que não admite réplicas:

Uma interjeição ou uma exclamação mostram que sua enunciação foi produzida de maneira direta, "arrancada à alma" por uma emoção ou uma percepção. 
Elas caracterizam a fala como constrangente, como algo inevitável, não sendo, pois, suscetíveis de uma apreciação em termos de verdade ou falsidade. Na medida em que se apresentam desse modo, elas pretendem constituir por si mesmas uma prova (prova indicial, tal como fumaça é prova do fogo). Daí o recurso a elas para dar ao discurso maior força argumentativa. (KOCH, 1993, p. 158)

Em geral, aqui são apontados erros de caráter hermenêutico, nos quais uma determinada concepção a priori do confucionismo e da cultura chinesa resulta em traduções distorcidas ou contraditórias.

Vejamos alguns exemplos:

a) Diz Mestre Legge: "Fine words and an insinuating appearence are seldom associated with true virtue" (...). Não se vá dizer que uma pessoa com uma cara decente e atraente, já não pode ser virtuosa. [p. 105]

b) Eis como Mestre James Legge traduziu o texto acima: (...). Quem olha para os caracteres do texto, e para esta versão, tem impressão de que é uma fantasia pegada. [p. 111]

c) Já agora, me lembro que o mesmo Waley traduziu o texto inicial do livro: "To learn and at due times to repeat what one has learnt". Isso não adianta nada. Nem está conforme com a mentalidade confuciana de estudar para a vida, e não apenas para saber. [p. 115]

d) Diz James Legge: "When the parties upon whom a man leans are proper persons to be intimate with, he can make them his guides and masters". Isso é inglês demais para meia linha de chinês. Não pode estar muito certo. [p. 121]

e) Diz Legge: (...). Eu acho que "yh xhuyn" quer dizer aqui Andar bem disposto, andar contente. Este significado também vem do Dicionário (no meu Dicionário de Semântica Universal, e não inventei!). [p. 141]

f) Ware, por seu lado, verteu da seguinte maneira: "Only princes have acted as assistants to our service. The Son of Sky has been majestic". Esse "Son of Sky" é uma aberração. [p. 161] 
g) Diz Mestre Legge: (...). Legge desorientou-se aqui; e o seu guia Tjur-Xe [Zhu Xi] não soube valer-lhe (...). O que fazem as más companhias! E ainda Legge quis aproveitar mais uma ocasião de desdoirar Mestre Confúcio. Ele próprio é que ficou desfeitado. E tenho pena. [p. 187]

h) Mestre Legge confessa encontrar dificuldade no "Se" e no "Sewn". A sua versão é: (...). Isso é pura ficção. [p. 213]

\section{Considerações Finais}

Nas refutações brandas, Guerra assume a voz do sinólogo que debate com seus pares em condição de igualdade. Não obstante algumas ironias, Guerra é sincero na sua admiração pelo trabalho de Legge. Assim lemos no final da Introdução ao volume das Escrituras Selectas:

Mas James Legge é para mim um velho companheiro de árduas viagens. Já lhe vou aguentando os seus. "fits of temper", como bem diz Charles San; e é sempre com saudade que dele me despeço. (GUERRA, 1980, p. 146)

Nas refutações enérgicas, temos o ethos missionário de Guerra que se exaspera com a tentativa de Legge de particularizar e restringir o confucionismo à China. Guerra, ao contrário, procura universalizar o humanismo chinês presente em Confúcio, fazendo ecoar a voz dos jesuítas na China nos séculos XVI e XVII. Assim lemos em meio à Notas Críticas essa queixa e esse desiderato:

Mestre Legge me perdoe, mas dá impressão que ele, apenas vê uma luz acesa, fora da Igreja, vai logo pôr-lhe o apagador em cima. (GUERRA, 1984, p. 221)

Se Mestre Legge tivesse um pouco mais daquela compreensão e abertura (shuy) que fazia parte do binómio de Confúcio, teria evitado a sua visão algo negativa dos textos clássicos chineses, e a imagem bastante negativa de Confúcio, que pôs a correr pelo mundo. Se eu conseguir melhorar um pouco esta situação, não será mau; e até Mestre Legge, já na Terra da Verdade, me há-de agradecer. (GUERRA, 1984, p. 197) 


\section{Referências bibliográficas}

BRAIT, Beth. "Bakhtin e a natureza constitutivamente dialógica da linguagem". In: BRAIT, Beth (Org.) Bakhtin, Dialogismo e Construção de Sentido. Campinas, SP: Editora da Unicamp, 1997, pp. 91-104.

BRANDÃO, Helena H. Nagamine. “Discurso e polêmica num debate político". Universidade de São Paulo, Revista do Instituto de Estudos Brasileiros, n. 37, 1994, pp. 129-43. Introdução à análise do discurso, $6^{\mathrm{a}}$ ed. Campinas, SP: Editora da Unicamp, 6 ed, 1997.

FIORIN, José Luiz. Introdução ao pensamento de Bakhtin. São Paulo: Editora Ática, 2006.

GUERRA, Joaquim A. de Jesus. Escrituras Selectas. Macau: Jesuítas Portugueses, 1980. Quadrivolume de Confúcio. Macau: Jesuítas Portugueses, 1984.

KOCH, Ingedore G. Villaça. Argumentação e linguagem, 3 ed. São Paulo: Editora Cortez, 1993.

. O texto e a construção dos sentidos, 7 ed. São Paulo: Editora Contexto, 2003.

SANTOS, Henrique Rios dos. Padre Joaquim Angélico Guerra, S.J. - Um globetrotter ao serviço de Deus e da China. Macau: Instituto Internacional de Macau, 2008.

SEGNIBO, Maria da Graça de Campos Mendes. "Os jesuítas nos alicerces da ponte China-Ocidente”. FFLCH-USP, Revista China em Estudo, n. 1, 1994, pp. 51-63. 